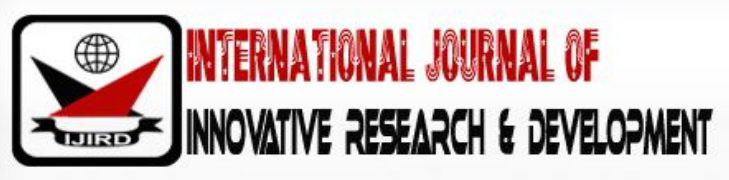

ISSN 2278 - 0211 (Online)

\section{Impact of Cooperative Instructional Strategies and Conventional Teaching Methods on Students Achievement and Interest in Upper Basic Education Science and Technology in Nigeria}

\author{
Michael Terfa Angura \\ Ph.D. Researcher, Department of Curriculum, Teaching, Benue State University, Nigeria \\ Venita Ojotule Abakpa \\ Ph.D. Researcher, Department of Curriculum, Teaching, Benue State University, Nigeria
}

\begin{abstract}
:
The study determined the impact of cooperative instructional strategies and conventional teaching methods on students achievement and interest in Upper Basic Education Science \& Technology. In Benue state Nigeria. A sample of 510 students out of 11,960 Upper Basic 8 \& 9 studentsfrom six (6) randomly selected government approved secondary schools was used for the study. The study adopted quasi-experimental control group design. Data was collected using Basic Science and Technology Students Achievement (BSTSAT) and Basic Science and Technology Students Interest Test (BSTSIT). These instruments were considered reliable for the study using Kuder-Richardson (KR-20) with the reliability value of 0.88 and 0.81 respectively. Two research questions and two null hypotheses guided the study. The research questions were answered using mean and standard deviation (SD) while the hypotheses were tested at 0.05 level of significance using analysis of covariance (ANCOVA). The study revealed that, there is significant difference in the mean achievement and interest of the students taught Basic Science and Technology using cooperative instructional strategies and those taught using conventional teaching methods i.e. the experimental group recorded high achievement and interest in the subject compared to the control group that recorded low achievement and interest in the subject.
\end{abstract}

Keywords: Cooperative, instructional, strategies, conventional, basic science \& technology, quasi-experimental

\section{Introduction and Background to the Study}

The teaching of science and Technology over the years has moved from teacher centered to student centered to ensure that learner participate actively during instruction. Hence, Science and Technology remains the life wire for sustainable development in every society all over the world (Ada, 2012). It is in attempt to join this global trend, that Science and Technology at the upper Basic Education Level in Nigerian schools as specified in the 9-year curriculum is redesigned and blended to inculcate into the learner the Scientific and Technological skills and attitudes as solid background and perquisite for sciences at the Senior Secondary School Level. Therefore, this target could easily be achieved if teachers are compelled to replace the conventional teaching methods like discussion and lecture with constructivist teaching strategies like co-operative instructional approaches (Jig - Saw and think pair share) where students could practically and actively be exposed to learning experiences that could actually enable them to construct knowledge for themselves (Schul, 2012).

A Cooperative instructional strategy is not only practical oriented but it makes teaching and learning effective and participative, because teaching is based on helping children progress from one level to another in a more sociable interactive environment that wouldinstill the approach right to get students to be independent learners.It is common experience in Nigeria that many teachers still adopt the conventional teaching methods as a medium of instruction in this 21 st century, against cooperative and blended teaching and learning approaches that create platforms where students are exposed to a more students centered learning experience (Debevec, 2006).

The conventional teaching methods or pre-history education methods were largely informal and consisted of children imitating, memorization, and recitation techniques thereby not developing their critical thinking, 
problem solving as well as decision making skills. It is obvious that Nigeria has gone past the pre-colonial era in all ramifications and the teaching pedagogies cannot be an exception (Ada, 2012).

Massive development can only be visible in all sectors of human endeavor in Nigeria, If teaching and learning methods are fully modernized to more socially, creative and practical approaches that could make teaching and learning real, and permanent (Moyinoluwa, 2014). Moller, \& Reitzes (2011) asserted that for effective learning to take place, a good method must be adopted by the teacher, because the background and knowledge of the students as well as the environmental and learning goals must be considered. Teachers are aware that students learn in different ways, which shows that only teachers who adopt cooperative and multiple teaching styles would actually retain information and strengthen understanding during instruction.

The curriculum of Basic Science and Technology in Nigeria is a product of the restructuring and integration of four Primary and Junior Secondary School subjects curricula namely; Basic Science, Basic Technology, Physical and Health Education and Computer Studies/ Information Communication Technology (FRN, 2012). This merger was based on the recommendations of the Nigerian Educational Research and Development Council (NERDC 2012). The Council pointed out the need for the integration of these subjects curricula as a result of the recommendation of the presidential summit on education in 2010, to reduce the number of subjects offered in Primary and Junior Secondary Schools; feedback from the implementation of the curricula in schools that identified repetition and duplication of concepts as the major cause of curriculum loaded; importantly the need to encourage innovative teaching and learning approaches and techniques that promotes creativity and critical thinking in learners; above all, the need to promote the holistic view of science and technology at the basic education level for better understanding of contemporary and changing world and needs to include emergent issues that are of National and Global Concern such as gender sensitivity, globalization and entrepreneurship (NERDC, 2012). The merger of many subjects to be taught as a single subject at the Basic Education level directly or indirectly called for a depart from the conventional teaching methods and styles to more proactive teaching strategies that would actually blend those subjects to be actually perceived by studentsas one.

Moyinoluwa, (2014) carried out an assessment of teaching and evaluation methods in the Federal Capital Territory (FCT) Abuja in the Basic Education Schools, and asserted that many teachers still adopt conventional teaching methods such as lecture, discussion, talk-chalk/ recitation methods as a medium of instruction.

VIKOO, (2011) Investigated the effects of conventional and co-operative learning strategies on the academic performance of senior secondary school Biology, the study concluded that the performance of students that used co-operative learning were far better compared to those that used conventional methods. This study was focused on the Senior Secondary classes with no reference to the foundation classes of upper Basic Education. Similarly, Oloyede, Adebowale \& Ojo (2012) researched on the effects of competitive, cooperative and individualistic classroom interaction models on learning outcomes in mathematics in Nigerian Secondary Schools. They also agreed that the students learning outcomes in mathematics are better promoted by cooperative and competitive strategies.Chainson, Kurumeh, and Obida, (2010) studied the effect of cooperative learning strategies on students retention in circle geometry in Secondary Schools. The study showed that, cooperative learning actually promotes the students retention in circle geometry.This shows that for the 9-year Basic Education Curriculum in Nigeria to be effectively implemented, the teaching methods should urgently be modified to include hands on instructional strategies for a deeper participation of students during classroom instruction. It is to fill the gap that the previous researches created by not giving much attention to Upper Basic Education Science and Technology which is the foundation of science subjects offered at Senior Secondary School level, that prompted this research.

\section{Purpose of the Study}

The purpose of the study is to determine the impact of cooperative instructional strategies and conventional teaching methods on student's achievement and interest in Upper Basic Education Science and Technology. Specifically the objectives of the study are;

- To find the mean achievement scores of student's taught Basic Science and Technology using cooperative instructional strategies and those taught using conventional teaching methods.

- To find the mean interest scores of student's taught Basic science and technology using cooperative instructional strategies and those taught using conventional teaching methods. 


\section{Research Questions}

The following research questions guided the study;

- What is the difference between the mean achievement scores of students taught Basic Science and Technology using cooperative instructional strategies and those taught using conventional methods?

- What is the difference between the mean interest scores of students taught Basic science and Technology using cooperative instructional strategies and those taughtusing conventional teaching methods?

\section{Hypotheses}

The following null hypothesis was tested:

- Ho1. There is no significant difference in the mean achievement scores of students taught Basic science and Technology using cooperative strategies and those taught using conventional teaching methods.

- Ho2. There is no significant difference in the mean interest scores of students taught Basic Science and Technology using cooperative instructional strategies and those taught using conventional teaching methods.

\section{Cooperative Instructional Strategies versus Conventional Teaching Methods}

Cooperative learning is an instructional method in which students work togetherin small, heterogeneous groups to complete a problem, project or other instructional goals, while teachers acts as guides or facilitators. This method works to reinforce a student's own learning as well as the learning of his or her fellow group members (Duplass, 2006). Conventional teaching or traditional teaching refers to a teaching method involving instructors and the students interacting in a face-to-face manner in the classroom. These instructors initiate discussions in the classroom and focus exclusively on knowing content in textbooks and notes. Students receive the information passively and reiterate the information to be memorized in the examination (Mc-Carthy \& Anderson, 2000).

The conduct of education in this $21^{\text {st }}$ century has been witnessed with a paradigm shift from convention teaching methods that promote face-to-face teaching where the teacher dominates all aspect of the instruction to a more cooperatively learning environment where the learner is in the center of the instruction (Moeller, \& Reitzes, 2011). The use of conventional or traditional teaching methods such as; Lecture, discussion, Talk chalk, Recitation methods etc. relies mainly on textbooks and whatever interpretation the teacher gives to back it up (Debevec, 2006).Johnson (2009) published five (5) elements essential for cooperative instructional strategies and students achievements as well as higher order social, personal and cognitive skills to facilitate students problem solving, reasoning, decision making, planning, organizing and reflecting. Similarly, Weimer (2002) posited that the conventional teaching methods could easily be face out of education if teachers are ready to incorporate and implement the following five key changes into their instructional practices.

\subsection{The role of the teacher}

Instead of having the teacher covering the syllabus from a-z in the classroom, the teachers shall encourage students to become active learners where their role changes from teacher to facilitators.

\subsection{The balance of power}

In learner-centered teaching, teachers start to share the activity making with the students. In such situation, students are involved more in learning process rather than having teachers to decide everything for the students.

\subsection{The function of content}

The content used in the classroom delivery is able to promote critical thinking skill, problem solving skill and to develop their learning skill and increase self-learning awareness beside the ordinary function which is to deliver the knowledge to students.

\subsection{The responsibility for learning}

In learner centered teaching environment, students are encouraged to play active role in learning where they will be aware of their learning responsibilities. Students do not feel being forced to look at the study materials and in fact they are motivated to be more independent and have controls on how they want to study. As such students need lectures lesser since they have responsibilities for learning. 


\subsection{The process and purpose for evaluation}

The evaluation adopted in the course works is able to promote learning and help students to develop their learning skills. Learner - centered teaching promotes the useof self-assessment or peer assessment because this can avoid the courses to be grade - oriented and evaluated by teachers only.

In order to completely replaced the conventional teaching methods with cooperative instructional strategies that would improve students achievement in any subject or course of study at all the levels of education Kangan (1989),Ross \& Smythe (1995), Giles \& Adrian (2003) and Schul (2012) posited a number of cooperative instructional strategies which include;

- $\quad$ Think - pair - share

- Jigsaw

- Jigsaw II

- Reverse Jigsaw

- Inside - outside circle

- $\quad$ Reciprocal teaching

- $\quad$ STAD - student team - achievement division

- Rally table

- $\quad$ TGT - Team game Tournament

- $\quad$ NHT - Numbered Heads Together

- $\quad$ Pair checks

- Three steps interview

- $\quad$ Round robin brainstorming

The common characteristics of cooperative instructional strategies which warrant teachers at all levels of education to adopt include;

- Heterogeneousgroup: -The teacher creates groups of diverse ability levels and backgrounds.

- Teachers Supervision: - The teacher monitors each group abilities to ensure that the students are not veering too far off task. He or she is always available to answerstudent's questions and guide them throughout the lesson.

- $\quad$ Positive Interdependence: - By setting group goals and working towards a reward or final learning outcome.

- Face-to-Face Interaction - Students are encouraged to use verbal and nonverbal communication to solve problems and explain learning material.

- Individual Accountability: - Students are accountable for their tasks and for assisting the whole group meets learning goals. This accountability is enforced through individualstudent's roles.

- Social Skills: The teachers establishes rules so that all students are respectful, speak in a manner appropriate to the classroom setting and utilizes their time wisely during group interaction.

- $\quad$ Group processing: - Students engage in reflection on how the group functioned during the activity.

- Evaluation; all activities both individual and group are completely assessed by the students and the teacher (Duplass, 2006 \& Schul 2012).

\section{Research Design and Procedure}

A quasi- Experimental of non-randomized, pre-test, post-test control group design was adopted for the study. The population of study was 11,960 upper basic 8 and 9 science and technology students of Benue State. A sample total of 510 students 300 male and 210 female drawn from six secondary schools in the three Education Zones A,B\& C of BENUE State were purposively chosen to ensure total coverage.Six (6) government approved secondary schools were selected, two (2) from each Education Zone through simple random sampling technique. The study considered only six (6) schools in order to maintain accuracy and transparency during the experiment. In each of the six (6) schools selected, students were further subjected to randomized sampling to form the experimental and the control groups respectively.

Basic Science and Technology Student's Achievement Test (BSTSAT) and Basic Science and Technology Student's Interest Test (BSTSIT) were used for data collection. The instruments were developed by the researchers, the both BSTSAT and BSTSIT consists of 30 multiple choice items taken from the 9-year Basic Education Curriculum for Basic 8 and 9 only. The 30 items each of BSTSAT and BSTSIT were scored on a four point 
scale of strongly agree (SA) $=4$ points, agree $(A)=3$ points, disagree (D) $=2$ points, and stronglydisagree (SD) 1 point. This was to clearly identify the accepted items and in reverse the rejected items. The items of the BSTSAT and BSTSIT were validated by three experts in the Department of Curriculum and Teaching Benue State University Makurdi.The BSTSAT and BSTSIT were determined using Kuder-Richardson 20 formula (KR-20) which yielded a coefficient value of 0.88 and 0.81 respectively. The research questions were answered using mean and standard Deviation scores while the hypotheses were tested at 0.05 level of significance using Analysis of Covariance (ANCOVA).

\section{Results}

\subsection{Research Question 1}

What is the difference between the mean achievement scores of students taught Basic Science and Technology using cooperative instructional strategies and those taught using conventional teaching methods?

\begin{tabular}{|c|c|c|c|c|c|c|}
\hline Group & $\mathbf{N}$ & Premean & Bstsat Sd & Postmean & Bstsat Sd & Mean Gain \\
\hline Experimental & 277 & 31.33 & 3.15 & 55.64 & 3.18 & 24.31 \\
\hline Control & 210 & 21.44 & 2.27 & 32.56 & 2.08 & 11.11 \\
\hline Total & 447 & & & & & \\
\hline Mean diff & & 9.89 & & 23.08 & & 13.10 \\
\hline
\end{tabular}

Table 1: Mean And Standard Deviation (SD) Scores of Student's Achievement in Basic Science and Technology Source: Field Report

Table 1 Shows that students taught Basic Science and Technology using Cooperative Instructional Strategies (CIS) had BSTSAT mean scores of 31.33 and 55.64 with standard deviation of 3.15 and 3.18 respectively. The students taught using Conventional Teaching Methods (CTM) had pre BSTSAT and post BSTSAT mean scores of 21.44 and 32.56 with SD of 2.27 and 2.08 respectively.

The summary of the achievement scores shows 24.31 mean gain for the experimental group and 11.11 mean gain for the control group with a mean difference of 13.10 which clearly indicated that the achievement of those in experimental group was higher, however this result is subject to further analysis by testing hypothesis 1.Ho1

There is no significant difference in the mean achievement scores of students taught basic and technology using cooperatives strategies and those taught using conventional teaching methods.

\begin{tabular}{|c|c|c|c|c|c|}
\hline Source & Some of square & df & Mean square & f & sig \\
\hline Corrected Model & 1261.133 & 2 & 575.152 & 1214.265 & 0.02 \\
\hline Intercept & 3713.712 & 1 & 3714.712 & 241.117 & 0.03 \\
\hline Pretest & 412.301 & 1 & 412.411 & 20.832 & 0.01 \\
\hline Achievement* & 321.567 & 1 & 322.567 & 145.312 & 0.07 \\
\hline Error & 240.530 & 371 & .410 & & \\
\hline Total & 35314.011 & 374 & & & \\
\hline Total Corrected & 67154.118 & 373 & & & \\
\hline
\end{tabular}

Table 2: analysis of covariance of student's achievement in treatment groups Source: SPSS version

Table 2 The ANCOVA analysis shows that the experimental group have F - value of 145.312 and significant value of 0.07 which is far higher than $p$-value of 0.05 that means $(\mathrm{P}=0.05<0.07)$. 
Base on this results the null hypothesis $\left(\mathrm{H}_{01}\right)$ which started that there is no significant difference in the mean achievement scores of students taught basic science and technology using cooperative strategies and those taught using conservational teaching methods is rejected. This clearly shows that there is a significant difference in the achievement of the students taught Basic Science and Technology using cooperative strategies and those taught using conventional teaching methods. The result has also confirmed the difference noticed in the mean achievement scores of the two groups in favour of the cooperatives instructional strategies.

\subsection{Research Question 2}

What is the difference between the mean interest of students taught Basic science and technology using cooperative instructional strategies and those taught using conventional teaching methods?

\begin{tabular}{|c|c|c|c|c|c|c|}
\hline Teaching Method & N & Pre-interest Mean & SD & $\begin{array}{c}\text { Post-interest } \\
\text { Mean }\end{array}$ & SD & Mean Gain \\
\hline CIS & 477 & 3.83 & 3.19 & 2.76 & 2.10 & 1.07 \\
\hline CTM & 127 & 1.37 & 1.23 & 1.36 & 0.35 & 0.01 \\
\hline Total & 564 & & & & & 3.86 \\
\hline Mean Diff & & 2.46 & & 1.4 & & \\
\hline
\end{tabular}

Tables 3: Mean and Standard Deviation of Students Interests In Basic Science and Technology.

Source: Field Report

Table 3 shows that students taught Basic Science and Technology with CIS got pre-interest and post interest mean scores of 3.83 and 2.76 with standard deviation of 3.19 and 2.10 respectively, while students taught with CTM got pre-interest and post - interest mean scores of 1.37 and 1.36 with standard deviation of 1.23 and 0.35 respectively. The total mean gained for the experiment group was 1.07 while that of control group was 0.01, with total mean difference of 3.86. This signifies high mean interest scores of students taught Basic Science and Technology using CIS compared to that of those taught using CTM.This result is also subjected to the final analysis by testing hypothesis 2 .

Hypothesis $2\left(\mathrm{H}_{02}\right)$ There is no significance difference in the mean interest scores of students taught Basic Science and Technology using cooperative instructional strategies and those taught using conventional teaching method.

\begin{tabular}{|c|c|c|c|c|c|}
\hline Source & Sum of Square & df & Mean & f & Sig \\
\hline Correctd Model & 58153.421 & 2 & 23521.214 & 2415.224 & 0.04 \\
\hline Intercept & 313.964 & 1 & 313.754 & 2415.224 & 0.00 \\
\hline Pretest & 354.625 & 1 & 354.625 & 11.148 & 0.02 \\
\hline Interest & 11.354 & 1 & 11.355 & 8.725 & 0.06 \\
\hline Error & 1454.143 & 372 & 2.136 & & \\
\hline Total & 228116.101 & 375 & & & \\
\hline Total corrected & 31550.217 & 374 & & & \\
\hline
\end{tabular}

Table 4: Analysis of Covariance on Student's Interest in Basic Science and Technology

Source: SPSS Version

Table 4 The analysis shows that F-value is 8.725 at the significant level of 0.06 , which is also higher than the P-value of 0.05 (i.e $0.05<0.06$ ). Therefore, hypothesis 2 which stated that there is no significant difference in the mean interest scores of students taught Basic Science and Technology using cooperative instructional strategies and those taught using conventional teaching methods is rejected.

By interpretation, the result shows significant difference in the interest demonstrated by the students taught Basic Science and Technology using cooperative instructional strategies compared to the low interest demonstrated by those taught using conventional teaching methods.

The result is also in agreement with the meanscores of Basic Science and Technology interest scale observed in the field report. 


\section{Discussion of Fundings}

The study determined the impact of cooperative instructional strategies and conventional teaching methods on student's achievement and interest at upper Basic Education Science and Technology. The findings of this study revealed that the experimental group performed significantly better than their counterparts in the control group in the Basic Science and Technology Students' Achievements Test. This is a clear indication that the use of cooperative instructional strategies into Basic Science and Technology teaching enhances students understanding and achievement in the subject. This significant achievement could also be due to the joy that they are exposed to more captivating approaches different from the traditional methods they are used to. This finding is in line with the findings of Vikoo (2011), whose findings using cooperative instructional strategies indicatedhigh academic performance in the Senior Secondary Biology.

Similarly, the findings of the study revealed that the experimental group performed significantly better than their control group counterparts in the Basic Science and Technology Students' Interest Test. This demonstration of high interest in the subject could be attributed to the fact that they were made to engage in different activities cooperatively during the pre-test and post-test lessons with their teachers serving as guides. This result is also in agreement with the findings of Chianson, Kurumeh \& Obida, (2010) and Adebowale \& Ojo (2012) whose findings from the use of cooperative strategies in teaching mathematics at the senior classes indicated a show of high interest and retention by the students.

\section{Conclusion}

The researchers drew the following conclusion in accordance with the findings of the study.

The use of Cooperative Instructional Strategies in the teaching of Basic Science and Technology seriously enhances student's achievement and interest in the subject. This is due to the fact that these approaches engages every student in the class actively thereby giving no room for observers, unlike the Conventional Teaching Methods where the students are compelled to sit and observe the teacher in most cases.

\section{Recommendations}

Based on the findings of this study, the researchers strongly recommends cooperative instructional strategies for effective teaching and learning in Nigeria, especially at the Upper Basic Education level, to help the students comprehend better the content of the various subjects precisely Basic Science and Technology,now that four different subjects are combined to form one.Also, seminars, workshops and conferences should be organized by government and other relevant agencies/stakeholders in theEducation sector to create more awareness for teachers to urgently replace Conventional Teaching methods with cooperative instructional strategies.

\section{References}

i. Ada, N. A. (2012). Implementation Challenges of Emerging Reforms in Teacher Education in Nigeria, Makurdi, De Choice Business Limited.

ii. Chianson, M. M Kurumeh, M.S Obida, J.A (2010) Effect of cooperative learning strategy on students' retention strategy in circle geometry in secondary schools in Benue State. American Journal of scientific and industrial Research Vol.2 (1) 33 - 36.

iii. Debevec, K. (2006) Learning strategies and performance in a technology integrated classroom, journal of Research on Technology in Education 38(3) 298 - 307.

iv. Dorgu T.E (2015) Different teaching methods, A parmacea for effective curriculum implementation in the classroom. International journal of secondary education Vol.36 (5) 77 - 87.

v. Duplass, J. (2006). Middle and High School Teaching: Methods standards, Best Practices, Boston: Houghton Mifflin Company.

vi. Federal Government of Nigeria (2013) National Policy on education Lagos, NERDC Press Plc.

vii. Giles, R.M \& Adrian, F (2003) Cooperative learning: The social and intellectual outcomes of learning in groups. London Farmer Press.

viii. Holt, D, Chips, B., \& Wallace, D. (1991) Cooperative learning in the secondary school: maximizing language acquisition, academic achievement, clearinghouse for Bilingual educational leadership Journal for the Education of the gifted 1(19) 63-82. 
ix. Johnson, D.W. (2009) An educational psychology success story; social interdependence theory and cooperative learning: Journal of educational research: 38(5) 365-399.

x. Kagan, S. (1994). Kagan Cooperative Learning 2nd edition. San Clementa. Kagan Publishing Company.

xi. Kose, S. Samin, A - Ergu - A \& Gezark (2010). The effects of cooperative learning experience on eight grade students achievement and attitude toward science. Journal of education 131(1) 169 - 180.

xii. Mayinoluwa J.D. (2014) An assessment of Teaching and evaluation methods used in the FCT Basic Education Schools. International journal of Innovative Research \& Development 3(5) 10 - 15.

xiii. McCarthy, J. P. \& Anderson, L. (2000). Active learning techniques versus traditional teaching styles: Two experiments from history and political science. Journal of Innovative Higher Education 24(4) 279-204.

xiv. Moeller, B and Reizes, T. (2011)Integrating Technology with student centred learning, Education Development center, Inc Quincy, MA Nellie Mac Education Foundation.

xv. Nigerian Education Research and Development Council (2012). 9-year Basic Education Curriculum, Basic Science and Technology for Upper Basic Education 7 to9. NERDC Press Plc.

xvi. Oloyede O.E, Adebowale, F.O \& Ojo, A.A (2012) Effects of competitive, cooperative and individualistic classroom interaction models on learning outcomes in mathematics in Nigerian Senior Secondary Schools. International Scholarly Research Journal Vol. 12 (16) 1885 - 5666.

xvii. Schul, J.E (2012) Revisiting and old friend, the practice and promise of cooperative learning for the Twenty First Century. The Journal of social studies (102) 88-93.

xviii. VIKOO, B. 2011 Effects of conventional and cooperative learning strategies on the Academic performance of senior secondary school Biology Students. Journal of Technology and Education in Nigeria. Vol.16 (2) 20 28.

xix. Weiner, M (2002) Learner centered Teaching:Five Key changes to practice 24(4) 89-95. 